sorbed into the blood, adding another depraving element, whose tendency is to set up remotely the condition present in the wound; and again, that the low state to which nutrition is reduced may render the veins vulnerable, so that these inflame, and produce purulent thrombosis, from which embolistr conveys portions to start abscesses elsewhere. And altbongh I do not prefer the lumping together of distinct alternatives into one view, yet it is probable that, in the genesis of pyæmia, this association of distinct elements in its causation actually does occur; and that pyæmia is first started by a depraved state of the blood, and that this reacts on the wound, causing in itself and in the vessels around the putrefactive and phlebitic changes which lead to those internal suppurations which give to pyæmia its distinctive characters and its name.

The view I have given, then, may be thus summed up:Simple embolism, or purulent absorption, or general fever due to contagion, severally form distinct varieties of what is called pyæmia; but in many cases, perhaps the majority, all these conditions exist together.

\section{EXTIRPATION OF A FIBRO-CYSTIC TUMOUR OF THE UTERUS, TOGETHER WITH THE UTERUS AND ITS APPENDAGES.}

\section{Bx E. H. TRENHOLME, M.D.,}

PROFRSSOR OF MIDWIFERY AND DISEASES OF WOMEN AND CHILDREY, DNIVBRSITY OF BISHOP'S COLLEGH ; ATNENDING PHXSICIAN TO THE WOMTN'S HOSPYTAL OF MONTREAL, ITC.

THE following synopsis of a report of a case of extirpation of the whole uterus for fibro-cystic tumour is forwarded to THE LANCET in the hope that it may be of interest to the profession, and to some extent induce surgeons to regard it with more favour than it has heretofore received, and also encourage attempts to save life when thus placed in imminent jeopardy of a sudden termination.

The patient, first seen by me in October, 1873 , is a mediumsized, well-developed, dark-complexioned, healthy, unmarried woman of thirty-four years. She is spare of flesh, has a good appetite, and sleeps well. The tumour from which she seeks to be relieved was first recognised in September, 1870, after an attack of what was called " inflammation of the bladder and gravel." It grew steadily and slowly for the next year, when it rapidly increased in size, but gave her no inconvenience till February, 1872, when she had a slight attack of menorrhagia. Hæmorrhage again occurred in May, also at two or three times during the year, the last of which was in July, 1873. Patient enjoys life, and has little trouble, except from the weight of the tumour, and at the menstrual periods, when there is a good deal of flatulence and pain, which passes off as soon as the flow is established.

The tumour fills the abdominal cavity, is firm to the touch, and the parietes over it are freely movable. There appears to be a fluid cyst at the upper part, between the umbilicus and ensiform cartilage, where there is much tenderness. Percussion gives a tympanitic note in either lumbar region, but over the growth the note is uniformly dull. Measurements : at the level of umbilicus, 41 in.; from ensiform cartilage to umbilicus, 9 in.; umbilicus to pubis, 11 in. ; right anterior superior spinous process to umbilicus, $10 \frac{1}{2}$ in.; left ditto, $9 \frac{1}{2}$ in. The os uteri could not be felt or seen per vaginam. The vagina reached above the brim of the pelvis in the direction of the left cotyloid cavity. The right ovary could be felt on the left side of the tumour on a level with the umbilicus. The bladder when distended with urine could be traced out over the tumour in the median line, and extending about three inches above the pubis.

Diagnosis. - From the ascertained facts stated, it was concluded that it was a fibro-cystic tumour of the uterus, probably springing out of the posterior and lateral part of the body of the organ.

Prognosis.-As suppuration had not supervened, and no dangerous symptoms were manifested, it was thought that life might be enjoyed for months to come; and, although the patient was anxious and ready to undergo the operation of excision of the tumour and uterus, such a course was not deemed warrantable, and she was sent home to enjoy herself till life became a burden, or some serious symptom demanding the operation presented itself.

Progressive symptoms. - Patient went on well as usual up to the end of January, 1874, when she noticed for the first time an offensive vaginal discharge, which gradually increased in quantity up to the end of February, when she had what she calls a congestive chill, that lasted for half an hour. This was followed by a high fever, which lasted about three hours, when a profuse perspiration supervened, which lasted ten hours, and, finally, this was followed by a severe headache that lasted a week.

From this time there has been increased pain during menstruation, continuous and offensive vaginal discharge, night-sweats, and a bad odour and taste in the mouth. After the attack the patient's strength and flesh rapidly diminished, so that by the end of a fortnight she was reduced almost to a skeleton. Towards the end of April and during May she recovered sufficient strength to come to Montreal on the $28 \mathrm{th}$ of the latter month. She now weighed $137 \mathrm{lb}$. The abdominal measurements were as follows:-Around the body, on a level with the umbilicus, $41 \frac{1}{2}$ in. ; ensiform cartilage to umbilicus, 10 in.; umbilicus to pubis, 12 in.; right anterior superior spinous process to umbilicus, $12 \mathrm{in}$.; left ditto, 11 in. Compared with the size of the tumour in October last, there is on an average an increase of about one inch in each of the measurements.

From the date of admission till 12th June, the day of the operation, attention was directed to the general condition of the patient. Effervescing carbonate of lithia was administered with satisfactory results in restoring the urine to its normal condition, as it had been scanty and highcoloured for some days past.

Operation (reported by Mr. JOHN T. DAvrs, student of Bishop's College, Montreal).-Anæsthesia was induced by chloroform and continued by sulphuric ether. An exploring incision to the extent of about six inches was made in the linea alba, with the customary precautions. Each point of hæmorrhage was at once controlled by Péan's forceps or fine hempen carbolised ligatures. An attempt was made to puncture the tumour at a point where indistinct fluctuation seemed to exist, and to draw off the fluid, which failed. The incision was then extended downwards to within an inch of the pubis, care being taken to avoid injuring the bladder; the incision was then extended upwards about three inches to one side and above the umbilicus, making the extent of incision about fourteen inches. The adhesions and vascular connexions, which were very extensive on the posterior and lower part of the tumour (among which was an attachment of the bowel to the extent of about ten inches), were chiefly divided by the actual cautery and knife, every point of hæmorrhage being secured by fine hempen ligatures cut off close to the knot. The uterine ligaments were divided by the hot iron, but this did not prevent persistent hæmorrhage from the right ovarian artery, which was ligated with considerable difficulty. The tumour, being sufficiently freed to be raised out of the pelvis, was then carefully separated from the neck of the uterus, and the latter enclosed in the wire écraseur, and then divided a little above the wire, at about one inch from the os, by the knife. The tumour being removed, the cavities of the abdomen and pelvis were carefully sponged out with carbolised water. The edges of the incision were brought together by eight deep interrupted sutures, and the same number of horsehair sutures superficially. The pedicle was transfixed by two steel needles crosswise of the abdomen, one passing through the centre of the pedicle, and the other, a figure of eight suture, embracing the edges of the incision and upper edge of the pedicle in its grasp. Carbolised lint was placed under the ends of the needles and over the wound. The abdomen was supported by broad strips of adhesive plaster passed over it from side to side. Over this was placed cotton wool, and all was secured in situ by a broad flannel roller.

At the completion of the operation, which occupied two hours and a quarter, alarming symptoms of collapse supervened, from which she rallied on the exhibition of stimulants. The patient was then moved to her bed, and a quarter of a grain of morphia given to secure rest, but its effect was to cause vomiting and so much gastric irritation that it was not repeated. Subsequently aconite was given for the purpose of checking the emesis, and encouraging the action 
of the skin, which it satisfactorily accomplished. At 10 P.M., the skin being moist, and pulse quick and full, veratrum viride was given to control the heart's action. It acted tolerably well, but had to be omitted as it induced severe vomiting. On the second day the bowels began to be distended with flatus. There was considerable nausea; tincture of capsicum relieved this very effectually. In the evening flatus escaped freely per anum. I need bardly say that the urine was drawn off every four or five hours, up to the evening of the third day, when she passed it without difficulty; the bowels also moved quite freely. On the fourth day she was doing well, but troubled with sore-throat and tendency to cough (the result of a cold caught the day before the operation), for which nux vomica was given with satisfactory results. On the sixth day she felt so well that she said she "would like to be out of bed." On the evening of the ninth day the pedicle separated, leaving a deep cicatrix, which gradually filled up. From this time up to the twentieth day, she was troubled with accumulations of pockets of pus in the parietes of the abdomen, around the cavity of the pedicle. These pockets of pus generally communicated freely with ulcers, but on those days that such was not the case there was a good deal of constitutional disturbance and fever. On the thirty-second day the patient walked across her room, and on the tbirty-fifth day walked down town to Victoria-square, some 250 or 300 yards. She weighed $102 \mathrm{lb}$, being $32 \frac{1}{2} \mathrm{lb}$. less than before the operation. From this date forward she gained flesh and strength rapidly, and is now (15th October) free from pains or any other infirmity. Has gained $19 \frac{1}{2} \mathrm{lb}$. since the 1st August, and enjoys life without hindrance.

The tumour weighs $16 \mathrm{lb}$, and springs out from the centre of the back part of the body of the uterus, somewhat to the left side. A No. 10 catheter can be passed through the os, and then through a fistulous opening communicating with a large cyst near the centre of the growth, but rather nearer the upper border. This cyst, when fresh, was full of pus, and holds about $32 \mathrm{oz}$. The growth throughont is of a dense fibroid character, and inseparably con. nected with the body of the uterus.

Victoria-square, Montreal.

\section{THE WET SHEET IN SCARLATINA.}

\section{BY JOHN TAYLOR, M.R.C.S., L.S.A.}

As the present high rate of mortality from epidemic scarlatina may justify practical suggestions prompted by experience, I feel it my duty to endeavour to excite the profession to a reconsideration of the remedial powers of the wet sheet as an auxiliary in promoting cutaneous elimination.

Though all agree as to the importance of promoting and sustaining cutaneous elimination in the prevention of cerebral, spinal, and other congestions, and, at a later stage, the disintegration of mucous membranes, dropsy, and glandular enlargements, yet this simple, powerful, and ready-at-hand auxiliary is unappreciated. Forty years' experience has assured me that this plain or medicated vapour-giving envelope affords the best external means for eliminating scarlatinal poison and preventing destructive sequelæ. promptly suppresses pyrexial heat and itching; produces sleep, with a soft secretive skin, more or less continuously; and enables the digestive organs to accomplish that great desideratum in the treatment of scarlatina-viz., absorption of highly nutritious food. It may be repeated, on the recurrence of the febrile paroxysm, two, three, or four times in twenty-four hours; the patient remaining enveloped from half an hour to an hour. Mothers and nurses who have witnessed its efficacy are most earnest in its repetition. My plan of procedure is to immerse a nightgown, slit up at the front, in hot water (balf a pint to a pint), pure, or medicated with a drachm or two drachms of tincture of capsicum, or in the infusion of three or four pods; or in mustard-water, the clear supernatant fluid from a tablespoonful of mustard to a pint of water; extending the gown over the feet by meane of a towel immersed in the same fluid, both to be wel wrung out and suddenly applied, and the patient quickly packed in two blankets previously placed on the adjoining sofa or bed; another blanket, or two pillows, or an eider down quilt covering all.

The medicated packing is preferable in the incipiency and at any other time to evoke the rash, and in cases of cerebral oppression, with pale skin, low pulse, and delirium Last month I had a case of this type, in which the mustard packing was applied. It did not elicit the rash, but it cured the delirium, raised an alarmingly depressed pulse, and re. stored the excretions. This effect was solely dependent on the medicated packing, as the patient, a girl of thirteen, could not swallow medicine or food, and enemata had not then been administered. With the aid of a tonic she made the best recovery of three in the same family, and had no sequelæ.

The auxiliary mode of treatment here defined is by no means intended to exclude the ordinary plan which every practitioner's experience has led him to select and rely upon; but I am of opinion that if packing is judiciously incor. porated with such reliable treatment, it will be the means of saving many lives that would otherwise be lost, and of diminishing the severity and duration of the sequelæ.

I further believe that in other cases of blood-poisoning the exhibition of medicaments cutaneously by vapour would in some degree neutralise the poison, aid its elimination, and, as in packing, soothe the whole nervous system. During a cholera epidemic in Liverpool I had part charge of a district where nearly all who first went into the hospital died. One woman, with cholera in the malignant form, was packed in a wet sheet with half a pound of mustard, and remained enclosed six hours, notwithstanding her imploring entreaties to be released. She drank copiously of iced water. The vomiting, purging, and cramps began to abate in two hours, and had ceased when she was unwrapped, presenting the ordinary lobster change from blue to red. Gastric fever, with great thirst, ensued for several days, when she recovered as a brand plucked from the burning.

Modern parliamentary mustard, deprived of capsicum and otber adjuvantia which made it formerly a condiment so famous, would not have answered the purpose. Doubtless, persevering cutaneous elimination is a great medical power.

Not only as an eliminator may the wet medicated envelope be used, but as an antispasmodic in the relief of pain and irritation in any of the membranes, mucous, submucous, or serous; with the aid of chloral, morphia, conium, belladonna, nux vomica, \&c., dissolved in the water, or sprinkled on any particular part of the wet sheet. It has the merit of antiquity from the ancient Romans, and among the farmers of Great Britain for the relief of colic and the inflammatory diseases of cattle. A sheet, wet with some herb decoction, or water sprinkled with turpentine, was thrown over the suffering animal, and enveloped by blankets, quilts, and overcoats, snatched from the beds on which " the rude forefathers of the hamlet slept." And, doubtless, many a pang was thus allayed and many a life preserved. Modern experience has witnessed the amazing relief procurable from the wet sheet, in its simple form, in pyrexial and glandular disorders, and from the medicated form in the zymotic and spasmodic affections. In stridulous croup, for instance, I have seen the mustard sheet act magically after other means more orthodox had failed. Its power is also potential in diphtheria simulating croup, and in strong doses, in inflammatory croup, sometimes averting the impending tracheotomy knife.

The suggestion to use this auxiliary plan of treatment should not be slighted because of its antiquity or of its having been used empirically. Many blessings, moral and physical, have fallen into desuetude, and require revivals to awaken a consciousness of their existence and utility; and this is one of them, lying neglected within our reach. Objection would be rational if the more primitive plan of enveloping the suffering man or beast within the skin of a newly killed animal were recommended; but when one so simple and close at hand, so easily adapted, so soothing, and so powerful as an auxiliary in the routine of medical treatment, is recommended, suffering humanity should have the benefit of it, especially where no self-interest prompts the recommendation-except the satisfaction of doing good by presenting the cup of cold water so typical of charity. Hope-street, Liverpool. 